
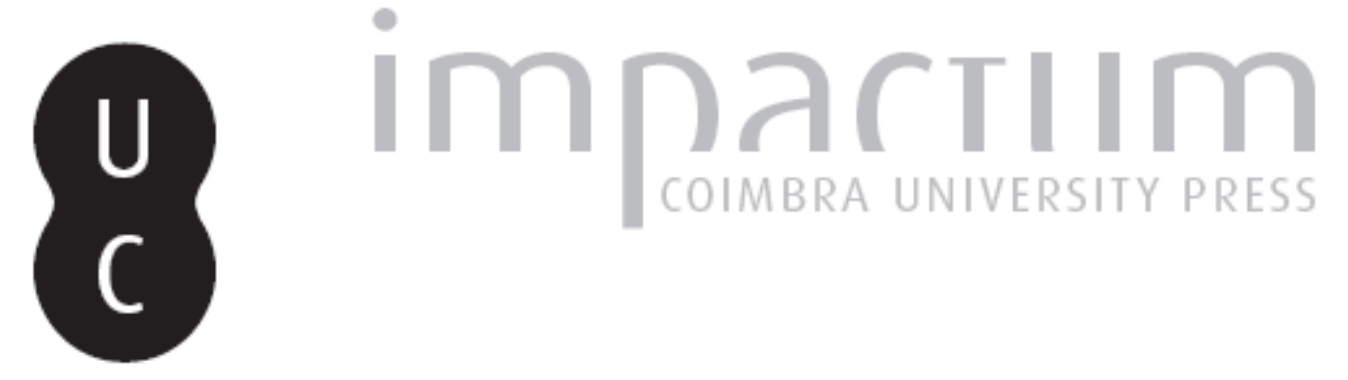

\title{
Os manuais de retórica entre os séculos xvi e xviii: apontamentos para um itinerário a partir do espólio da BPE
}

Autor(es): $\quad$ Martin, Armando Senra; Teixeira, Cláudia; Amado, Casimiro

Publicado por: Imprensa da Universidade de Coimbra

URL

persistente:

URI:http://hdl.handle.net/10316.2/41478

DOI:

DOI:https://doi.org/10.14195/0872-2110_60_9

Accessed : $\quad$ 26-Apr-2023 14:36:45

A navegação consulta e descarregamento dos títulos inseridos nas Bibliotecas Digitais UC Digitalis, UC Pombalina e UC Impactum, pressupõem a aceitação plena e sem reservas dos Termos e Condições de Uso destas Bibliotecas Digitais, disponíveis em https://digitalis.uc.pt/pt-pt/termos.

Conforme exposto nos referidos Termos e Condições de Uso, o descarregamento de títulos de acesso restrito requer uma licença válida de autorização devendo o utilizador aceder ao(s) documento(s) a partir de um endereço de IP da instituição detentora da supramencionada licença.

Ao utilizador é apenas permitido o descarregamento para uso pessoal, pelo que o emprego do(s) título(s) descarregado(s) para outro fim, designadamente comercial, carece de autorização do respetivo autor ou editor da obra.

Na medida em que todas as obras da UC Digitalis se encontram protegidas pelo Código do Direito de Autor e Direitos Conexos e demais legislação aplicável, toda a cópia, parcial ou total, deste documento, nos casos em que é legalmente admitida, deverá conter ou fazer-se acompanhar por este aviso.

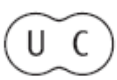


COIMBRA • 2015

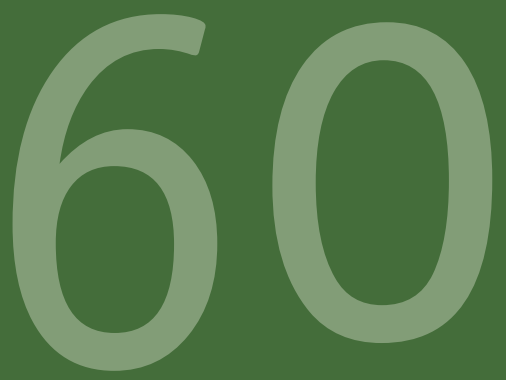

\title{
BOLETIM DE
}

\section{ESTUDOS CLÁSSICOS}

\author{
ASSOCIAÇÃO \\ PORTUGUESA \\ DE ESTUDOS \\ CLÁSSICOS \\ INSTITUTO \\ DE ESTUDOS \\ CLÁSSICOS
}




\section{OS MANUAIS DE RETÓRICA ENTRE OS SÉCULOS XVI E XVIII: APONTAMENTOS PARA UM ITINERÁRIO A PARTIR DO ESPÓLIO DA BPE}

RHETORIC HANDBOOKS FROM 16TH TO 18TH CENTURIES:

LANDMARKS IN AN ITINERARY BASED ON THE HOLDINGS OF THE PUBLIC LIBRARY OF ÉVORA

ARMANDO SENRA MARTINS

CEC; UNIVERSIDADE DE LISBOA - UNIVERSIDADE DE ÉVORA

adsm@uevora.pt

CLÁUDIA TEIXEIRA

CECH-UC - UNIVERSIDADE DE ÉVORA

caat@uevora.pt

CASIMIRO AMADO

DEPARTAMENTO DE PEDAGOGIA E EDUCAÇÃO - UNIVERSIDADE DE ÉVORA casimiro@uevora.pt

Resumo: Este texto pretende divulgar um conjunto de manuscritos, depositados nos fundos da Biblioteca Pública de Évora, escritos entre os séculos XVI e XVIII, que ilustram a evolução no ensino da retórica. 
Palavras-chave: BPE; retórica; manuais.

Abstract: This paper intends to introduce a set of manuscripts deposited in the Public Library of Évora (BPE), written between the sixteenth and eighteenth centuries, that document the evolution in the teaching of Rhetoric.

Keywords: BPE; Rhetoric; textbooks.

A retórica, enquanto componente indispensável da formação de um jovem, independentemente de este se destinar à carreira secular ou eclesiástica, foi alvo de uma produção textual extensa, que documenta os debates culturais e ideológicos que se desenvolveram ao longo dos séculos. Dessa produção, seleccionou-se, a partir do espólio da Biblioteca Pública de Évora (BPE), um pequeno grupo de textos cuja leitura permite reconstituir uma linha de evolução no ensino e nas tendências da retórica entre os séculos XVI e XVIII. O ponto de partida deste itinerário passa obrigatoriamente pelo manual de Cipriano Soares, S.J. De facto, o De arte Rhetorica, libri tres, ex Aristotele, Cicerone, Quintiliano praecipue deprompti, publicado em 1562 (tendo conhecido várias edições posteriores) ${ }^{1}$, constitui-se como obra de charneira que combina a tradição retórica do Renascimento com a cultura da Contra-Reforma.

${ }^{1}$ Flynn 1957: 257, observa que o compêndio foi publicado mais de 207 vezes entre 1562 e o século XVIII. 


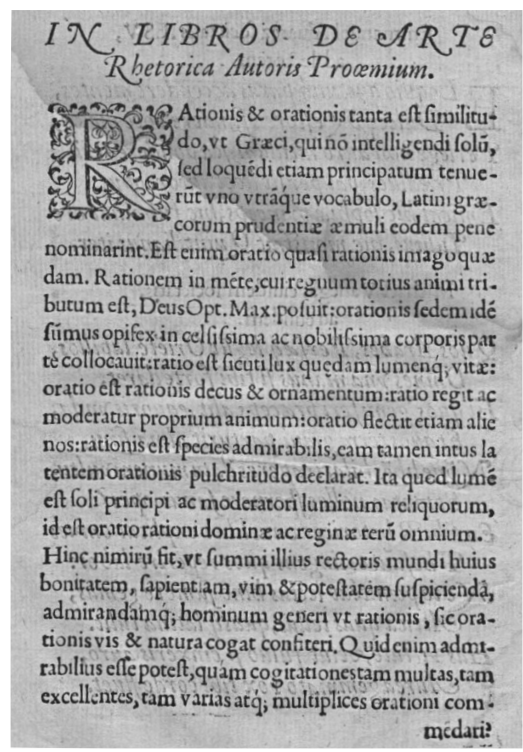

Cipriano Soares, De arte Rhetorica...

Dividido em três livros (o primeiro sobre a inuentio, o segundo sobre a dispositio e o último sobre a elocutio), o tratado constitui um exemplo de retórica pós-tridentina, uma vez que preconiza um ideal de eloquência cristã ${ }^{2}$ que se define por uma ruptura com algumas práticas que o autor atribui à eloquência clássica: ${ }^{3}$

«Mas para que tanto maior possa ser a utilidade a colher da eloquência, esta deve ser cuidadosamente expurgada pelos preceitos cristãos. De facto, e como um bom agricultor faz a uma vide que se torna bravia e que se espalha com força para todos os lados, dominando-a

${ }^{2}$ De arte Rhetorica, Proémio, fól. 6: His tot, tantisque deletis maculis continuo existet illa diuina et coelestis Christianae eloquentiae pulcritudo. De arte Rhetorica, III, fól. 116: (...) illi profecto maximos et uberrimos fructus percipient, qui eam [sc. eloquentiam] ad Dei Op. Max. cultum ac venerationem diligentissime contulerint.

${ }^{3}$ Flynn 1956: 369 comenta: «Thus by means of the classics Soarez hoped to inculcate intellectual and moral ideals, purify them by Christian directives, and keep them elevated above pagan abuses.» 
com o ferro, para assim a tornar mais produtiva em termos de fruto e melhor em termos de aspecto, assim também a eloquência, se lhe for amputada a inanidade dos erros em que caiu, por culpa dos homens que ignoravam as leis divinas, recuperará então a sua imagem admirável. Corte-se, pois, a licença de mentir, coisa severamente proibida pelos preceitos divinos mas facultada ao orador por Quintiliano e pelos antigos oradores; ampute-se a ousadia e esse péssimo vício de atacar os outros com injúrias, ofensas, maledicências, nas quais até Demóstenes e Cícero caíram; apare-se-lhe a arrogância e o vão apetite pelo elogio que embota a acuidade do espírito; faça-se ver que é perverso atirar poeira para os olhos dos ouvintes, para que não vejam a verdade, e corromper o voto e a opinião, o que era prática corrente de oradores gregos e romanos.» ${ }^{4}$

A retórica deixara, na verdade, de ser uma competência exigida para a vida política, tal como o fora para Bruni, Piccolomini e outros autores do primeiro humanismo: «Extinta qualquer forma de humanismo cívico, consolidada uma cultura do livro impresso, veio a retórica profana a alhear-se da doutrina da acção, mesmo quando reduziu a arte à elocutio e à pronuntiatio. Se a retórica do primeiro humanismo, fundada nos exemplos de Isócrates e de Cícero, se justificava pela sua relevância política, depois, ao longo do séc. XVI, acabou por conformar-se com uma

${ }^{4}$ De Arte Rhetorica, Proémio, fól. 5v-6: Sed quo maior utilitas ex eloquentia percipi possit, Christianis praeceptis diligenter ea purganda est. Vt enim bonus agricola vitem, quem syluescit et in omnes partes nimia funditur, ferro coercens, tum fructu laetiorem, tum aspectu pulchriorem redit: sic eloquentia si amputetur errorum inanitas, in quos delapsa est vitio hominum diuinas leges ignorantium suam admirabilem speciem recuperabit. Excidatur igitur mentiendi licentia, quam seuere diuinis praeceptis interdicta oratori Quintilianus et antiqui rhetores concedunt: amputetur procacitas et vitium illud teterrimum lacerandi alios probris, contumeliis, maledictis, cui utinam ne Demosthenes et Cicero tantopere indulsissent, resecetur arrogantia et inanis laudis appetitus, quem aciem animi perstringit, intelligatur iniquum esse tenebras auditoribus offundere, ne verum perscipiant, et suffragium atque sententiam dicendo corrumpere, quodam Graecis et Romanis oratoribus est factitatum. 
finalidade puramente educativa; de ars dicendi a retórica transforma-se em ars scribendi.» ${ }^{5}$

A obra singulariza-se pelo seu formato didáctico, facto que, nos séculos posteriores, não seria despiciendo para a sua consagração como manual de referência para o ensino da retórica. ${ }^{6}$ A este aspecto acrescem ainda dois elementos que tornam o De Arte Rhetorica um texto tão importante: em primeiro lugar, o facto de esta obra não ser um comentário aos tratados latinos, mas um manual devidamente estruturado; em segundo lugar, o facto de incorporar, em paralelo com elementos ciceronianos e de Quintiliano (como o indicam o título e o proémio da obra), 7 a doutrina aristotélica. Todavia, relativamente às fontes, o autor intervém de forma, por vezes, crítica, marcando a distância que o separa delas. ${ }^{8}$

Relativamente à sua influência, uma das evidências de que a obra granjeou uma considerável divulgação pode ver-se na proliferação de desenvolvimentos (de que é exemplo a obra de João de Mendonça, Prelecções de Rhetorica feitas sobre as do Padre Cipriano Soares com mais difusão, 1626, BPE, cód. CXII/1-3 d), e de resumos que, conforme afirmou Aníbal Pinto de Castro, eram usados no ensino da retórica de nível pré-universitário a alunos que não se destinavam à vida eclesiástica9 - resumos que, por outro lado, mostram também, de acordo com o

\footnotetext{
${ }^{5}$ Pereira 2010: 239.
}

${ }^{6}$ Flynn 1957: 257, observa: «Experience as a teacher of classical rhetoric had convinced Soarez that the classics were not designedly written for beginners. Still, so effective were the classics as a tool for teaching rhetoric that he meant to reduce the chief rules and pertinent illustrations to a diet that youthful students could digest and assimilate.»

${ }^{7}$ De Arte Rhetorica, Prefácio ao leitor, fól. A iii, v.: (...) his tribus libris dicendis praecepta, quantum exiguae ingenii mei vires efficere et consequi potuerunt, complexus sum, ut iuuarem adolescentes ad legendos Aristotelis, Ciceronis et Quintiliani doctissimos libros, quis eloquentiae fontes continetur.

${ }^{8}$ Sobre as fontes de Cipriano Soares, vide Pereira 2012: capítulo 3.4.

${ }^{9}$ Pinto de Castro 1973: 144: «A retórica fazia parte do ensino de colégios jesuítas como matéria para formar pregadores, mas também para a formação de jovens que não se destinavam à carreira eclesiástica e que eram admitidos nesses colégios antes do nível universitário. Documentam o ensino da retórica a esse nível os mss da BPE (...)» 
mesmo autor, a adaptação do manual ao gosto barroco. De facto, as matérias teóricas, áridas, passam a ser apresentadas de uma forma mais apelativa, graças ao uso de ornamentos barrocos, patentes nos títulos rebuscados e imaginativos (e que, mais tarde, suscitarão a acrimónia de Verney ${ }^{10}$ e criativas formas de exposição, desenvolvendo, por exemplo, as metáforas de jardim, banquete, música, etc., como bem o exemplifica o manuscrito anónimo da Biblioteca Pública de Évora, intitulado Fasciculus ex Cypriani viridario decerptus, sive Rhetoricae compendium (BPE, cód. CXIII/1-27).

Embora Cipriano Soares se tenha tornado um modelo para o ensino retórico no século XVII, os manuais e compêndios produzidos em contexto jesuítico não se cristalizaram nesse modelo, tendo incorporado, por um lado, tratadistas contemporâneos e, por outro, literatura coeva (e.g. Camões, Sannazzaro, John Owen, Pierre-Juste Sautel, Bernard Bauhuis, etc.).

Exemplo desta evolução constitui o códice, datado do final do século XVII, intitulado De arte Rhetorices (BPE, cód. CXIII/1-5). Este tratado, embora, à semelhança do que sucede na Arte de Soares, trate as duas primeiras partes da retórica (inuentio e a dispositio), contém desenvolvimentos específicos que pretendem, por um lado, responder à necessidade de fornecer aos alunos elementos didácticos de apoio à composição latina e, por outro lado, aprofundamentos de aspectos particulares da retórica como, por exemplo, os afectos. Este último elemento, que em Soares é tratado de forma abstracta e ocupa um capítulo de pouco mais de uma página, é alvo de uma análise muito mais particularizada. Segundo o autor, o orator deve considerar, em uma adaptação de Cícero aos tempos modernos e à retórica eclesiástica, as características da audiência e as circunstâncias da pregação. Deste modo, são relevantes elementos como o sexo (pois as mulheres são mais propensas às lágrimas), as inclinações (quase sempre os filhos se assemelham aos pais ou às amas), os temperamentos (biliosos, fleumáticos...), os tempos

${ }^{10}$ L. A. Verney, Verdadeiro Método de Estudar. Vol. II: Estudos Literários, Lisboa, Sá da Costa, 1950: 119. 
(uma coisa convém ao Carnaval, outra à Quaresma...), o estatuto social (e.g. se se pretende convencer um nobre ou um rico a fugir do pecado, convém dizer que essa fuga é um feito glorioso; se for a um pobre, será melhor dizer-lhe que é um ganho...), as idades, etc.

Outro exemplo desta inflexão barroca da retórica pode ver-se no códice intitulado Orphea Rethorices cithera in quinque chordas seu partes distributa et eloquentiae plectro emodulata (BPE, cód. CXIII/1-7), dividida em cinco partes (sc. inuentio, dispositio, elocutio, memoria e pronuntiatio) e «cantada com a lira da eloquência». Além da imagem barroca presente no título, ${ }^{11}$ o manuscrito apresenta as particularidades de traduzir para português alguma terminologia latina (e.g. Propositio quam lusitane uocamus assumpto) e de fazer abundante uso de Camões para a ilustração dos preceitos retóricos. ${ }^{12}$

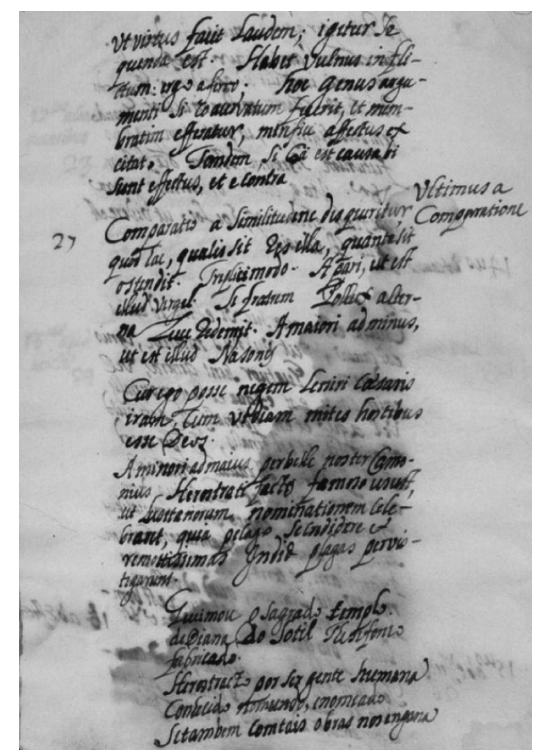

Orphea rethorices cithera in quinque chordas...

${ }^{11} \mathrm{Na}$ mesma linha, embora com outra imagem, a do banquete, se integra o manuscrito anónimo Dialogidia Retoricae (BPE, cód. CXIII/1-4).

${ }^{12}$ Sobre este assunto, vide Gomes Pereira 1974: 160-178. 
No contexto da retórica pós-jesuítica, encontra-se, nos fundos da BPE, um Compendio das Instituiçoens Rhetoricas de Quintiliano (BPE, cód. 278 Manizola), assente em um paradigma inteiramente distinto. Não obstante o título, a obra não advoga um regresso a Quintiliano, mas apresenta antes um comentário que toma como ponto de partida o texto do autor latino, incorporando constantes referências a teóricos do séc. XVIII, como Heinécio e Balthasar Gibert.

Os Apontamentos de Rhetorica (1762) de José Caetano de Mesquita (BPE, cód. 494, Manizola), postilhas das lições proferidas no Colégio dos Nobres, constituem um testemunho do sistema de ensino da retórica após a reforma de Pombal. A estrutura da obra afasta-se da tradicional divisão dos tratados, privilegiando-se agora a necessidade de atender a critérios filológicos, de forma a garantir a autenticidade autoral e histórica das fontes. Com efeito, a preocupação em estabelecer as fontes essenciais para cada área disciplinar é uma constante neste tratado, como bem o expressam os seguintes excertos:

«Para a Logica hé excelente o nosso Vernei, Heinecio, Genovesi; todos elles trataraõ esta parte da Filosofia sem as futilidades dos Escolasticos; ensinando somente o util e ajuntando os preceitos da boa Arte Critica. Para a Ethica o Heinecio, ou Corsini, que escreveu elegantemente. Para a Politica os oito livros de Aristoteles, e a Politica de Bossuet tirada das Escrituras. (...) Para a [gramática] Latina temos a excelente Minerva de Sanches, e a nova Gramatica impressa em Barcelona, 1758. (...) Dos preceitos desta Arte [sc. História] escreveu Vossio, e Sciopio; mas melhor

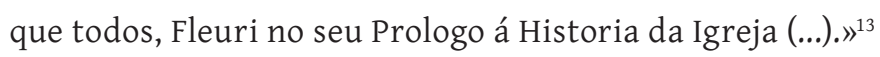

\footnotetext{
${ }^{13}$ Apontamentos de Rhetorica, fóls. 51r-51v. Outros exemplos podem colher-se em vários passos da obra, nomeadamente, em f. 51v: «A Critica he Arte que nos ensina a examinar bem a verdade dos factos, e o merecimento dos Autores, e das suas obras. Desta Arte escreveu Walchio na sua Diatribe Filosofica § 7, Genovesi na sua Logica, e o melhor pela clareza, e brevidade, Fleuri no lugar citado.»; fól. 57v: «em Portugues [depois de ter falados nos livros históricos latinos] Fr. Luis de Souza, de quem tratamos quotidianamente, Joaõ de Barros, e outros.»
} 
O carácter iluminista do texto está, além disso, patente nas referências teóricas adoptadas, entre as quais pontuam Gibert, Heinécio e o próprio Verney, bem como na crítica ao gosto da oratória barroca. ${ }^{14}$

O anónimo Tratado da Compozição (BPE, cód. 234 Manizola), também escrito em português, apresenta um conjunto de preceitos e teorias pensados para a língua portuguesa (embora tenha sempre presente autores como Aristóteles, Cícero e Quintiliano). A obra foi composta depois de 1768, no ambiente cultural pombalino, como o comprova a remissão para a Dedução Cronológica e Analítica.$^{15} \mathrm{O}$ tema do tratado, "a composição", é definido pelo autor como «huma conveniente e apta estructura, ou das palavras ou das oraçoens por causa do ornato. Consta de tres partes: ordem, junctura e numero.» O autor parte da composição entendida ao nível microtextual, ou seja, da articulação de palavras, passando para o nível da oração, e deixa para a parte final da obra o tratamento de características macrotextuais, como o estilo. Os modelos de estilo, que o autor recomenda, são Jacinto Freire de Andrade, a Dedução Cronológica e Analítica e até Racine, provavelmente por influência de Boileau.

Com estas obras do período pombalino termina uma linha que começara em Cipriano Soares e que se ampliara na produção barroca, observando-se agora uma tendência para sintonizar a retórica com os novos ideários filosóficos e com os novos horizontes culturais, os quais, além

\footnotetext{
${ }^{14}$ Apontamentos de Rhetorica, fól. 58r-58v: «[... depois de mencionar os Antigos] tambem podemos ler alguns modernos para o pulpito; dentre os Franceses Massilon, e Bordallue; e dos nossos Diogo de Paiva, e o Vieira, lendose com a advertencia Critica de que, deixandose arrastar do mau gosto do seu tempo, cahio em agudezas pueriz, e raciocinios falsos, e muitos defeitos, que facilmente podem enganar aquem naõ tiver estudado. Para a Advocacia, dentre os Franceses, Falon e Patru; dentre os nossos naõ sei nenhum, de cujos arrazoados, que andem impressos, nos possamos servir para exemplares.»

${ }^{15}$ Tratado da Compozição, p. 37-38: «Os exemplos saõ a cada passo nos nossos Auctores Portuguezes, por ser ordinariamente esta composiçaõ mais accomodada à nossa Lingoa: podese ler o principio da devisaõ nossa da deducçaõ chronologica, que offerece hum excelente exemplo.»
} 
do cânone clássico, sempre valorizado, incorporam cada vez mais literatura e metaliteratura europeia, parte dela escrita em línguas modernas.

\section{BIBLIOGRAFIA}

Castro, A. P. (1973), Retórica e Teorização Literária em Portugal. Do Humanismo ao Neoclassicismo. Coimbra, Centro de Estudos Românicos.

Gomes Pereira, J. (1974), “Camões nas escolas jesuíticas do séc. XVIII”, In Actas do Congresso A arte em Portugal no séc. XVIII. II Secção - Literatura. III Secção - Música, Bracara Augusta, vol. XXVIII, ${ }^{\circ 5}$. 65-66.

Flynn, L.J. (1957), “Sources and influence of Soarez' De Arte Rhetorica”, Quarterly Journal of Speech, 43.3: 257-26.

Flynn, L. J. (1956) “The De Arte Rhetorica of Cyprian Soarez, S. J.", Quarterly Journal of Speech, 42.4: 367-374.

Pereira, B. F. (2010), “A Actio no De Eloquentia de Tomé Correia (1591)," in Belmiro, F. P. e Várzeas, M. (eds.), Retórica e teatro: a palavra em aç̧ão. Porto, Universidade do Porto, 235-248.

Pereira, B. F. (2012), Retórica e eloquência em Portugal na época do Renascimento. Lisboa, Imprensa Nacional-Casa da Moeda. 